\title{
On China's Cultural Eco-environment of Translation
}

\author{
Wenying Zhang \\ College of Foreign Language Studies, Harbin University of Science and Technology, China \\ Email: zwy5803@yahoo.com.cn \\ Yangyang Zhou \\ College of Foreign Language Studies, Harbin University of Science and Technology, China
}

\begin{abstract}
The process of translation is a process of communication between different cultures. This process includes not only cultural integration in communication but also deep-rooted cultural conflicts. The discrepancies between different cultures are unfolded in the activity of translation. The activity of translation is inevitably influenced by the cultural eco-environment which, in China includes traditional culture, living customs and ways of thinking which have existed for thousands of years, and the development of translation is inevitably influenced by many ecological factors of culture. This essay discusses China's cultural eco-environment of translation in the perspective of translation ecology from two aspects of ecological environments of translation: the input of foreign cultures and the output of Chinese cultures.
\end{abstract}

Index Terms - translation ecology, cultural eco-environment, foreign cultures

\section{INTRODUCTION}

Although the tide of globalization caused the degradation of the ecological system of language, it leads to the forward development of the translation ecosystem, as the well-known translation theorist Michael Cronin (2003) pointed out that globalization does not mean the extinction of nations, but the coexistence of integration, diversification, globalization and localization. Therefore, translation, as a kind of medium of cultural communication, should take effect in the process of globalization; it also conveys the unique value of language and culture during the process of developing culture diversity and multi-national consciousness. Under the trend of globalization, China's translation ecology has greatly changed, not only in such external environmental factors as natural environment, social environment, and normative environment, but also in such internal environmental factors as individual physiology and psychology. This essay discusses China's cultural eco-environment of translation in the perspective of translation ecology from two aspects of ecological environments of translation: the input of foreign cultures and the output of Chinese culture.

\section{The INPUT ECO-ENVIRONMENT OF FOREIGN CULTURES}

\section{A. Respecting Cultural Diversity and Taking a Broad-minded Attitude toward Foreign Cultures}

Cultural globalization has become a new trend in the development of human culture. Language and culture have the characteristics of interaction with and restriction of each other. The vitality of culture lies in its ability to spread. As a tool of spreading culture, language imposes great restriction on the spread of culture, and provides the power for the survival of culture. The relationship between translation and culture is intricate. Translation itself is a part of culture. Translation activity is a social practice of interaction between different cultures. Because of cultural spread, especially the spread of national culture, the translational process would create new words, new forms of expression, thus, culture not only affects but also restricts the language of translation (Ji Shuxian, 2009). The development of translation is inseparable from the cultural eco-environment of translation. There exists a co-evolutionary relationship between them.

The formation of Chinese culture is actually the result of integration with domestic multi-national cultures as well as continuous integration with "foreign" cultures. In the process of today's cultural globalization, the cultures of different countries, regions, and nations make positive dialogues in a more open attitude so as to achieve constant development in mutual communication and to further accelerate the trend of cultural integration. From the development process of the cultural communication between China and western countries, it can be found that there are contradictions and conflicts as well as convergence and complements between different cultures (Pan Haiying, 2009). This is the present macroscopic input eco-environment of foreign cultures in China. China's translators have realized that "Only by putting translation on the level of globalization and comprehensively understanding the discrepancies between different cultures, can the translators break the deadlock, make culture play an active role between different cultures, and make all the human wisdom crystallization shine. Ecological translation in the context of globalization does not only play the role of protecting the balance of natural ecology, but also help to strengthen the localization of language communities and the linkages between communities." (Zu Lijun, 2007, p. 89-92). 
In recent years, Chinese translators have begun to attach importance to ecological translation in the context of cultural globalization. In the process of inputting foreign cultures, they value ecological features of language and culture, namely, green attributes, cleanness and ethics. The translators should regulate and restrict the use of language, close the door to "impurities" of other nations' languages and cultures, keep the cleanness of its own nation's language and culture. To maintain the purity of language and culture is to protect the ecological balance and ethics of language and culture. In this process, ecological translation is particularly important.

China's translators are deeply influenced by Chinese traditional cultures and ethics in attitude toward foreign cultures in their translation practice. In dealing with cultural discrepancies, Chinese translators insist on "respecting the fact of cultural diversity, seeking unity in differences with a broad-minded attitude towards 'foreign' cultures, achieving mutual understanding, learning from each other through dialogue." (Xu Jianzhong, 2008, p.52). This has become a recognized moral norm in China's translation field. The process of overcoming the thought of self culture-centered is to build a cultural bridge or to create a bidirectional angle of view through the interaction of different cultures (Han Hong, 2002). In the context of cultural globalization, China's translators explore the discrepancies between different cultures continuously to face the integration of global cultures, and to adjust the cultural countermeasures in an active attitude. They try to not only absorb the essence of multiculturalism, but also strengthen the spiritual values of national culture, so as to realize the modernization of national culture when communicating and integrating with foreign cultures and constantly innovate to create an advanced culture with Chinese characteristics.

\section{B. Opposing Cultural Hegemony, Persisting in Cultural Consciousness}

Nowadays, in the atmosphere of economic, scientific and technological globalization and cultural diversity, China's cultural eco-environment of translation is still affected by the mainstream culture from the western countries. Wang Enke (2007) pointed out the reason for this phenomenon as follows: "In addition to the characteristics of the culture itself, cultural influence is mainly determined by the national economy, science and technology, politics, and military power which are associated with culture. The discrepancies of economy, science and technology, politics, and military power will be inevitably displayed their effect in terms of cultural influence. Therefore, some cultures are in a superior status while others in an inferior status" (p. 18). We can clearly see that cultural hegemony and the phenomenon of cultural colonialism shown by strong culture is still quite serious in the translation field. It is still a universal phenomenon that the strong cultures exclude or assimilate the week cultures.

As messengers who communicate between different cultures, China's translators lay special emphasis on "cultural consciousness" in the process of communicating with strong cultures. The so-called cultural consciousness refers to the recognition and promotion of one's own cultural traditions, identifying one's own cultural values, compared with other cultures' values, to promote human culture. If there is no such kind of culture consciousness, it is very difficult to complete the mission of understanding, digesting and disseminating foreign cultures. The Chinese translators should not only shoulder the responsibilities of taking initiative to consciously safeguard the histories and traditions of their own culture to make them continue and carry forward, but also pay attention to introduce fresh alien cultures to their own national culture, and continuously increase the intrinsic motivation for the survival and development of Chinese cultures. Dealing with "foreign" cultures, Chinese translators advocate adopting the "use doctrine" attitude proposed by Mr. Lu Xun, that is, accepting the good and rejecting the bad, and to work out the cultural strategy of both actively promoting the building of national culture and interacting with and countering foreign cultures, as well as to implement the strategic adjustment of industrial policy to build a cultural industry system which is suitable for China's national conditions and to form an important force which could contend with the massive invasion of Western culture, in order to avoid the convergence of culture (Zhang Jieyun, 2004).

\section{Filtering Foreign Cultures}

The so-called cultural filtration refers to a phenomenon that "when the cultural information of original text is converted into target text, it will inevitably go through the filtration of cultural field of target text, thus a certain degree of refraction phenomenon occurs." (Hua Xianfa, 2009, p.121). This kind of cultural filtration is an inevitable and unavoidable phenomenon of cultural variation in translation activities, and it is influenced by such ecological environments as translators, social politics, cultures, economies, and by such factors as temporal, spatial, and language distances. Any life pattern exists in a specific historical background, and takes specific customs, habits, institutions, and tradition as a precondition. Translation is a realistic activity of language application carried out in the life pattern, and "language is a habit, a system, a kind of social culture" (Gai Xiaolan, 2009, p.152). Therefore, translators cannot understand and grasp meanings of the text without considering the social, historical, and cultural factors in the translation process. Cultural filtration is a universal phenomenon in translation activities. It can be said that the process of translation is the process of conflicting and grinding between two different cultures, and is the process of cultural filtration. The occurrence of cultural filtration should be constrained by translation ethics, and should not be allowed to magnify, otherwise there will be no "faithfulness" at all.

Chinese translators filter foreign cultures based on the recognition of cultural discrepancies and the respect for different cultures following the rule of equal dialogue, and for the purpose of establishing harmonious dialogue between different cultures and exploring the best way of cross-cultural communication in their translation practice that Chinese translators filter the foreign cultures. This is entirely in line with the translation ethics which is generally accepted by all 
states in international cultural communication. Of course, people should not neglect the tendency of culture while being fully aware of cultural discrepancies. With the process of economic integration and the development of the internet age and globalization, the shrinking, combination and symbiosis of cultural differences will become the main features of cultural phenomenon (Han Hong, 2002). The filtration to foreign cultures by Chinese translators has the characteristics of times, individualism, consciousness, and unconsciousness. "The so-called times means that the translators dispose the original text with the consciousness of their era unconsciously; while the individualism means that the translators often read and translate the original text according to their personal will." (Hua Xianfa, 2009, p.126). It is easy to understand the reasons which cause the phenomenon of cultural filtration. Most of the original texts' background of its times has changed when being translated. The translators will be inevitably constrained by ecological environments such as politics, cultures, and translation theories in their era, coupled with the differences of the literacy, interest, cognitive abilities, and life experiences of the translators, so the phenomenon of cultural filtration will inevitably occur when the translators interpret and reconstruct the background, characters, and psychological features of the original text. In fact, the target language produced in the field of the original language is a new language form created in the cultural context and artistic atmosphere of the original language. Therefore, the target language form is very different from the original language. The translator should try to overcome his or her limitations, get rid of conventional influence, and give less subjective opinions in language expression as much as possible (Gai Xiaolan, 2009). "Conscious cultural filtration refers to the change of the expressions, figurative images, literature conceptions of the original language in different degrees etc. to cater to the nation's cultural mentality or succumb to external forces and, while unconscious cultural filtration is to read and handle the original text based on the inherent concept in the inner world of the translator." (Hua Xianfa, 2009, p.127).

The scope of filtering foreign cultures is quite broad for Chinese translators. It often touches upon political, traditional, religious, and geographical, values, and customs. For example, different cultural values will become obstacles in translation when being reflected in different forms of languages. Larry A. Samovar and his co-authors have compared the East-West cultural values from twenty-nine aspects, such as personality, motherhood, etc. in their book cross-cultural communication (2000), and found up to twenty-five discrepancies. These discrepancies will be inevitably filtered in the cultural field of target text in various degrees in translation. In the specific process of translation practice, the forms of filtering foreign cultures by Chinese translators are various in kind, such as cultural misunderstanding, over-representation, under-representation, selective translation, adapted translation, and modification. To reduce the impact of cultural filtration, the translator should have a better understanding of the original text, and strive to truly understand the original text, "to achieve the conversion of the author's emotional space and time, truly and effectively convey the author's original intent." (Gai Xiaolan, 2009, p.153). The translator should try to choose the appropriate translation strategies to convey the discrepant features of the original text, to make translation work fresh and exotic, and to show the unique charm of the original work. "Before translating a text, the translator should understand and grasp social, cultural and even customary patterns of the author and works of his respective era as much as possible, as well as the period of historical described in the works, comprehensively understand and research the author's idea of life, ideological tendency, artistic point of view, aesthetic characteristic and language style, etc.” (Song Xiaochun, 2006, p.89).

\section{The Output ECO-EnVIRONMENT OF Chinese Culture}

\section{A. Focusing on the Promotion of the Fine Traditions of the Nation}

National factors fall within the category of cultural ecology. It refers to the totality of a nation's inherent characteristics, sentiments, beliefs and habits. China's cultural eco-environment, such as traditional cultures, customs, and thinking models formed for thousands of years, will inevitably influence the translation activity. The three words translation theory: "faithfulness, expressiveness and elegance" proposed by Yan Fu, which is rooted in the Chinese literary tradition, is in line with Chinese thinking, habits, and norms. China's translators shoulder the historical mission of promoting the fine traditions and style of Chinese nationality and overcoming the national weakness.

The output of Chinese culture is mainly carried out by the activities of Chinese-foreign translation. The Chinese-foreign translators should realize that translation of Chinese works should adapt to the need of the nation's revitalization. Only by rooting the Chinese-foreign translation and its research in its own nationality, can the Chinese culture be introduced into the world through the translation of literature in such fields as politics, sociology, philosophy, law, education, history, and finance, thus providing a medium for the world to understand China. China's translators should pay more attention to understanding and inheriting the fine traditions and style of Chinese nationality. Thus they can play an active role in Chinese-foreign translation. Their contributions are mainly reflected in upholding the following principles: First, Chinese-foreign translators should emphasize the adherence to the principle of supremacy of the national interests and the overall interests, and promote the unselfish sense of social responsibility and mission; second, they should have national self-esteem and pride while learning all useful things of other nations, observe the principle of promoting the Chinese culture while admitting its reality gap, make China's traditional culture communicate with the world, and form a good ecosystem with an atmosphere suitable for outputting Chinese cultures; third, the output of Chinese cultures should stick to the "three close to" principles in international communication. The so-called "three close to" principles refer to (1) close to China's actual development, realistically reflecting China's 
modernization process; (2) close to the needs of overseas audience for information about China, providing foreign audience with the information about China comprehensively, multi-dimensionally, objectively, and chronologically; (3) close to the thinking and language habits of foreign audience, studying foreign cultures and psychological thinking mode of foreigners, noting the discrepancies between Chinese and foreign cultures, and translating according to the thinking habits and language habits of foreign audience, so as to achieve the best effect of spreading Chinese cultures. Fourth, the translators should adhere to the translation principle of highlighting and strengthening exotic characteristics and ethnic characteristics of original culture, produce "authentic" translation based on maintaining the original meaning; fifth, they should promote moral principles of self-discipline and devotion to practice. Chinese people attach great importance to strengthening the cultivation of personal moral quality, which is a unique culture of Chinese traditional ethics. Chinese translators should not only pay attention to cultivating self-knowledge, but also focus on self-personality cultivation, and correctly treat the national culture: neither being arrogant and advocating nationalism, nor being self-denying, exaggerating the national weakness, and producing national inferiority.

\section{B. Trying to Change the Weak Status of Chinese Culture and Make China Go Global through Chinese-foreign Translation.}

Chinese culture belongs to the weak side in world culture. Compared with the connotation and profoundness of Chinese culture itself, its external spreading and the influence in the world fall much behind. We have to face such a reality that international communication and spreading of Chinese culture is in a serious cultural deficit status. Taking books for an example, the China's import and export trade deficit of books has been about 10:1 for many years. Books are mainly exported to some Asian countries and regions. In 2005, the total export of the books, newspapers and periodicals is U.S.\$32.87 million, and the import is U.S.\$164.18 million. This gap objectively reflects the ecological imbalance of our work in Chinese-foreign translation, the gaps and deficiencies in Chinese-foreign translation talents' training, and the problems and challenges faced by Chinese-foreign translators. In the new century, China's political and economic integration with the international community are increasing. The world is paying close attention to China's development. Since the reform and opening up, the work of Chinese-foreign translation has seen gratifying achievements in political, economic, cultural, diplomatic, press, publishing and other fields of China. Our Chinese-foreign translators translate the work of the Party and state leaders as well as diplomatic files into a variety of foreign languages and transmit them to the world. People in more and more regions of the world can read newspapers, books, and magazines translated by Chinese translators, hear the voices of a variety of foreign languages of China Radio International, and watch foreign TV programs broadcast by China Central Television. In recent years, China has launched the "China Book International Promotion Program" and published "Greater China Library", which have aroused widespread concern both at home and abroad and made efforts in creating a favorable ecological environment of Chinese-foreign translation.

Language is the precipitation of culture, while lexicon and semantics are inevitably stamped with the national culture, which in turn implies connotations of national culture. Translating these works involves communicating and transplanting alien culture in order to achieve equivalent conversion of pragmatic meaning to realize cross-cultural exchange. In this process, as the cultural bond, the translators should be duty-bound to complete the mission to show the unique style and features of every region (Gai Xiaolan, 2009). China's translators have clearly realized that in order to make China known by the world, to go global, and to accurately reveal China and its culture to the world in the process of modernization, the work of Chinese-foreign translation will play a key role in achieving this. China needs to take great efforts to cultivate a large number of high-quality Chinese-foreign translation talents to accelerate the development of China's foreign international career. Only by doing this can a harmonious ecological environment of Chinese-foreign translation be built up, and can the Chinese culture go global on a large scale.

\section{CONCLUSION}

"Culture is the main regulatory environment to translation ecology. Since translation is developed in culture, it will be influenced by a variety of cultural ecological factors. Meanwhile, translation plays an important role in cultural transmission, dissemination, development and creation." (Xu Jianzhong, 2009, p.42). To create a balanced, harmonious cultural eco-environment of translation, Chinese translators should be able to understand the rich cultures behind the languages used in translation, and they should not only treat foreign cultures with respect, but also be quite familiar with the unique ways of communication with foreign cultures. More important is that translators strive to promote the fine traditional culture of Chinese nationalities, understand the discrepancies between Chinese cultures and foreign cultures, try not to make these discrepancies become cultural barriers, and truly realize the integration of Chinese culture with world culture.

\section{REFERENCES}

[1] Bao Huinan. (2001). Cultural Context and Language Translation. Beijing: China Translation \& Publishing Corporation.

[2] Gai Xiaolan. (2009). Reflections on Meaning Viewpoints of Wittgenstein in Translation. Foreign Language Research, 6,150-153.

[3] Han Hong. (2002). Cross-cultural Concept of Foreign Language Teaching in the context of Globalization. Foreign Language 
Research, 1, 105-111.

[4] Hua Xianfa. (2009). The Phenomenon of Cultural Filtering in Translation. Edited by Gengshen Hu. Translation and Cross-cultural Communication: Integration and Innovation. Shanghai: Shanghai Foreign Language Education Press.

[5] Ji Shuxian. (2009). Intercultural Awareness in Foreign Language Teaching. Nei Jiang Ke Ji, 11, 195-217.

[6] Larry. A. Samovar. (2000). Communication Between Cultures. Beijing: Foreign Language Teaching \& Research Press.

[7] Michael Cronin. (2003). Translation and Globalization. New York \& London: Routledge.

[8] Pan Haiying. (2009). The Conflict and Integration between Chinese and Western Cultures in the Context of Cultural Globalization. Changbai Journal, 5, 158.

[9] Song Xiaochun. (2006). A Study of the Intersubjectivity and the Translator. Foreign Language Research, 1, 89-92.

[10] Wang Enke, Li Xi and Feng Xia. (2007). Cultural Perspective and Translation Practice. Beijing: National Defence Industry Press, 18.

[11] Xu Jianzhong. (2008). Translation Ecology. Beijing: China Three Gorges Publishing House.

[12] Zhang Jieyun. (2004). Cultural Globalization and New Development of Chinese Culture. Journal of Ningxia Communist Party Institute, 6 (3), 62-64.

[13] Zu Lijun. (2007). Ecological Translation in the Context of Globalization. Foreign Language in China, 4 (6), 89-92.

Wenying Zhang was born in Changchun, China in 1958. He received his Master degree in comparative literature and world literature major from Jilin University Changchun China in 2002.

$\mathrm{He}$ is currently a professor in Harbin University of Science and Technology, Harbin China. His major publications: On the Essence of English Technical Neologisms Translation, Beijing: Chinese Science \& Technology Translators Journal, 2009. Translation Strategies of Medical Health Care under Multicultural Context, Proceedings of the 18th World Congress of the International Federation of Translators, Beijing: Foreign Language Press, 2008. Research interests: studies of theory and practice of translation and interpretation, translation studies of EST, translation studies of Cross-cultural in pragmatics,

Prof. Zhang is now an expert member of Translators Association of China. From 1997 to 2001 he was a member of National English Teaching Steering Committee of Higher Education employed by National Ministry of Education.

Yangyang Zhou was born in Ke Shan, Qiqihar, China in 1986. She received her Bachelor degree in English Major from Harbin University of Science and Technology, China in 2009. She is now a postgraduate in Harbin University of Science and Technology, China. 